\title{
Self-help books
}

\author{
Susan Quilliam
}

\section{Background}

I have to admit that, as an author of self-help books myself, I simply assume they're a good idea. And when, a while ago, the Radio 4 consumer programme You and Yours invited me to the studio to comment on such books, I was thrilled. (I was even more thrilled when one of my own volumes was, in the course of the programme, favourably reviewed!)

But in all seriousness, I was still more thrilled to learn that the hook for the programme was a series of recent initiatives to introduce books into general practitioners' (GPs') surgeries, for patients to borrow, read, learn and inwardly digest. What a fabulous idea, I thought - and indeed, both the programme itself and the ensuing listener feedback were extremely positive.

\section{... a tackling of issues you may feel embarrassed to ask about.}

But all good ideas deserve a critical eye - and so, albeit as an insider, here is my attempt to cast just such a view. Is it a good idea to have patients reading up on medical topics off their own bat? As ever for this series of Journal articles, I went straight to the horse's mouth, the horses in this case being a selection of patients and GPs - though I do believe that the points I make here also apply to health professionals and care settings other than the GP practice.

\section{Enthusiasm in principle}

My patient sample was randomly selected, but was by definition self-selected to be a book-buying market. All the respondents had read a medical or psychological self-help book at some time in their lives, and their comments were extremely positive

They were particularly enthusiastic about the impact the books had had on their own management of their medical conditions. Books gave them facts, guidelines on diagnosis and treatment, easily understandable information and additional or alternative help to self-manage the condition.

\section{My mentioning books was not always} that well received.

Further, books provided not just a factual but also an emotional resource, giving "comfort ... reassurance ... empowerment ... a feeling of control ... a tackling of issues you may feel embarrassed to ask about". The first-person accounts that such books often contain were particularly useful: "motivating ... helping you feel you are not alone ... helping you through the night".

J Fam Plann Reprod Health Care 2005; 31(3): 243-244

Cambridge, UK

Susan Quilliam, BA, Cert Ed, MNLP, Freelance Writer, Broadcaster and Agony Aunt

Correspondence to: Ms Susan Quilliam.

E-mail: susan@susanquilliam.com
I turned then to the professional viewpoint, with a sample of GPs. Almost all thought that self-help books were a good idea. The GP comments were encouragingly reminiscent of the patient comments, in saying that: "knowledge is empowering ... books help patients take responsibility for their own health ... enables understanding ... help by making problems seem less personal". They also echoed the patient viewpoint that books were often helpful in offsetting a shortage of GP time and a plethora of long waiting lists.

\section{Wariness in practice}

In short, both patients and professionals seem to have a highly positive attitude towards self-help books. So we can expect a long line of well-informed patients using these books to inform their consultations then? Well, actually, no. Only some of my patient sample had mentioned a self-help book in the surgery and the majority of my responding GPs reported that they had never had a patient doing so.

Why? Why, for all their enthusiasm, were my lay respondents so wary of taking the initiative here? It was partly because the books they had bought were only relevant to "minor medical conditions" that they didn't want to bother their GP with. And it was sometimes because the book they had read was on a topic that they were too "embarrassed and uncomfortable" to bring to their GP.

\section{Books help by making problems seem less personal.}

But there was also a theme of anxiety - a wariness of mentioning 'self-help' to a professional for fear of a negative response. And horrifyingly, in exactly half my patient accounts, this fear was based on past experience: "I got a feeling of fear ... unease would be a better word ... that I had investigated things myself". "My mentioning books was not always that well received." "My GP was more put out than pleased." "Being well informed means 'neurotic and pushy' to some doctors." Ouch.

\section{Trust the patients}

In fact, double ouch. I'm convinced that any such negativity, even if in a minority of professionals, is not only unfortunate, but also misguided. We shouldn't block our patients' attempts to use self-help books - instead we should trust them to use those books properly.

And I believe we can trust them. Because almost everything I heard from the patients I talked to suggests that there is no reason for professionals to feel wrongfooted. The evidence is that lay people judge self-help books in a remarkably balanced way.

Patients were aware of personal bias given by the author. They were aware of misinterpretation by the reader. They were aware that books can get it wrong.

Patients are also aware of the risk of hypochondria: "A headache can become a brain tumour ..." and of more than one horror story of anxiety and upset being caused by a scare mongering or patient-blaming self-help tome. 
At the opposite end of the scale, patients are also aware that "you shouldn't self diagnose ... books can make you believe you can treat yourself without professional help". In fact, every patient actively wanted the professionals' viewpoint as first line of attack, with the book as second line. "I don't want a book instead of treatment ... I would want the GP's input too ... I would like to read, then discuss...". What these patients are asking for is not a way to supplant expert care, but extra help to manage their condition.

\section{Patient-professional co-operation}

In particular, almost every patient who commented wanted GPs themselves to suggest books. This, it seemed, would be the ideal way forward - for the recommendation to come from the professional, followed up by the lay person in the knowledge that they were on the right track.

\section{Books help patients take responsibility for their own health.}

The standards asked for in these recommendations were high - patients would want recommended books to be only those that a GP themselves had read, those that were relevant rather than generic, those that followed up on the GP's advice, and those that allowed the patient to take more responsibility for their own treatment. In short, patients wanted to use books to "develop a partnership" with the professional.

One can argue against this, and one or two professionals did so. One can argue that professionals have enough to do without having to trawl through self-help books on behalf of their patients. I have a lot of sympathy for this objection, though the guidelines given in Box 1 make some suggestions as to how to meet it.

One can argue also that such a partnership may cause trouble. If patients are encouraged to read round their condition it will mean that they are more armed if they want a struggle, and indeed three of my patients had used books to "argue points ... argue for NHS treatment ... get the correct treatment".

\section{Being well informed means 'neurotic and pushy' to some doctors.}

But first, if patients are indeed being given the wrong treatment, why should they not use books to challenge the professionals? And second, in my opinion, occasional conflict is a small price to pay for the reward of betterinformed, better-resourced patients, who are fully enrolled in their treatment rather than passive, compliant consumers. And I'm delighted to say that the health professionals I talked to almost universally agreed with me on this point.

Hence we seem to be at least singing from the same hymn sheet on this one. For patients, self-help books are a great resource that they are able to use usefully and sensibly. For professionals, such books could not only save time, but crucially can both resource and involve patients.

\section{Taking it further}

One way to encourage patients to use self-help books is to have your own practice library. That may seem a daunting task, but Dr Andrew Tresidder, who has set up the practice library at Springmead Surgery, Chard in Somerset, UK, suggests some simple guidelines (Box 1).

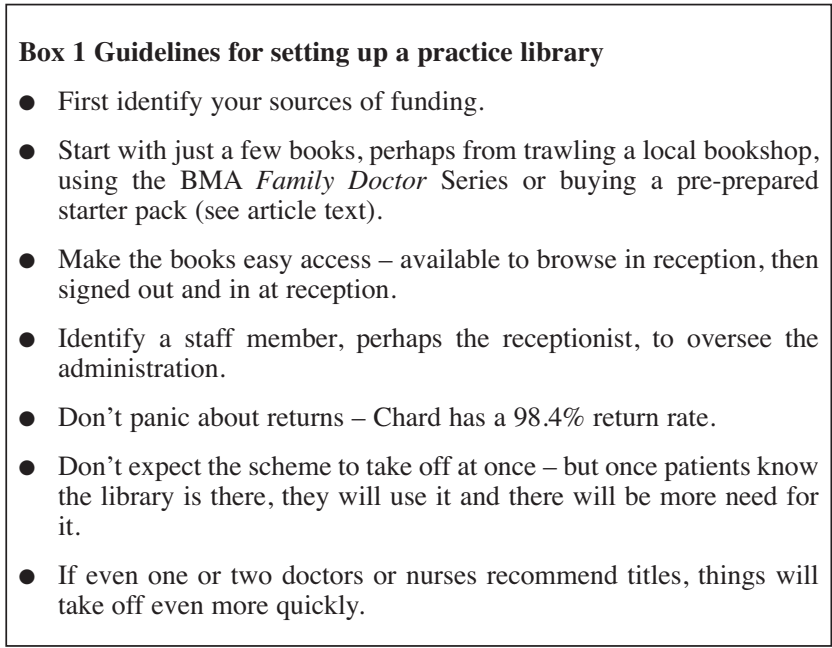

If you are panicking about the time investment needed to recommend books personally, you'll be interested in a scheme run by Cygnus Books, a not-for-profit bookseller who can provide GP surgeries with a starter pack of books pre-vetted by GPs, and then follow up with a regular 'offer' on recent, vetted publications. Cygnus also provides a freeof-charge magazine listing relevant books. Contact Geoff Napier for further information (e-mail: info@cygnusbooks.co.uk).

A new scheme in Dorset and Cardiff allows GPs to 'prescribe' self-help books for patients as part of their treatment - with no charge if patients then borrow the book from their local library.

\section{Recommended books}

A number of books were mentioned specifically by either patients or doctors as examples of helpful good practice (Box 2).

Box 2 Recommended books
- The Real Rules: How to Find the Right Man for the Real You by
Barbara De Angelis (Harper Collins, £6.99)
- Secrets About Life Every Woman Should Know: Ten Principles for
Spiritual and Emotional Fulfillment by Barbara De Angelis (Harper
Collins, £7.99)
- Boundaries: When to Say Yes, When to Say No to Take Control of
Your Life by Henry Cloud (Zondervan Publishing House, £8.99)
- Hiding From Love: How to Change the Withdrawal Patterns that
Isolate and Imprison You by John Townsend (Zondervan Publishing
House, £6.99)
- Allen Carr's Easy Way to Stop Smoking by Allen Carr (Penguin
Books, £6.99)
- Bulimia Nervosa and Binge-eating: A Guide to Recovery by Peter
Cooper (Constable and Robinson, £7.99)
- Confidence: Finding It and Living It by Barbara De Angelis (Hay
House, £6.99)
- Your Change, Your Choice: The Integrated Approach to Looking and
Feeling Good Through the Menopause - and Beyond by Michael
Dooley (Hodder Mobius, £12.99)
- Gael Lindenfield's Self-esteem Bible: Build Your Confidence Day by
Day by Gael Lindenfield (Element Books, £7.99)
New Toddler Taming: The World's Bestselling Parenting Guide by
Christopher Green (Vermilion, £12.99)

\section{Editor's Notes}

Susan’s new book, Body Language ( $£ 12.99$, Carlton Books Limited), is available now.

A follow-up article exploring patient use of medical websites will appear in the next edition of the Journal. 